\title{
Tribological Behavior of Ni-Based WC-Co Coatings Deposited via Spray and Fuse Technique Varying the Oxygen Flow
}

\author{
H. Jiménez $\mathbb{D},,^{1,2}$ J. J. Olaya $\mathbb{D}^{1}{ }^{1}$ and J. E. Alfonso $\mathbb{D}^{3}$ \\ ${ }^{1}$ Department of Mechanical Engineering and Mechatronics, Universidad Nacional De Colombia, Street 45, 26-85, \\ Bogotá, Colombia \\ ${ }^{2}$ Research Group in Energy and Materials (REM), Faculty of Mechanical Engineering, Universidad Antonio Narino, \\ Bogota, Colombia \\ ${ }^{3}$ Ciencia De Materiales y Superficies, Physis Department, Universidad Nacional De Colombia, Street 45, 26-85, Bogotá, Colombia
}

Correspondence should be addressed to J. E. Alfonso; jealfonsoo@unal.edu.co

Received 10 May 2020; Accepted 24 March 2021; Published 20 May 2021

Academic Editor: João P. Davim

Copyright (c) $2021 \mathrm{H}$. Jiménez et al. This is an open access article distributed under the Creative Commons Attribution License, which permits unrestricted use, distribution, and reproduction in any medium, provided the original work is properly cited.

The tribological behavior of Ni-based WC-Co coatings is analyzed. The coatings were deposited on gray cast iron substrates in a spray and fuse process using SuperJet Eutalloy deposition equipment, varying the oxygen flow conditions in the flame. The crystallographic structure of the coatings was characterized via the X-ray diffraction (XRD) technique. The microhardness was measured on the surface and in cross sections of the coatings by means of a Knoop microhardness tester. The topography and the morphological characteristics of the coatings and the tribo-surfaces were examined using scanning electron microscopy (SEM) and confocal microscopy, while the chemical composition was measured by means of energy-dispersive X-ray spectroscopy (EDS). The tribological behavior of the coatings was examined via a cohesion-adhesion scratch test, using cross sections of the coatings. Furthermore, two wear tests were carried out, using the pin-on-disk method under ASTM G99 standard and an ASTM standard G65 sand/rubber wheel abrasion wear test. The wear of the coatings showed a close relationship to the porosity in the metal matrix; since then, in the abrasive wear test, a high porosity is related with lower hardness in the coatings; likewise, a low hardness is related with a high wear.

\section{Introduction}

WC-Co coatings are frequently used in wear-resistance applications due to their tribological properties $[1,2]$. These coatings have been deposited mainly using thermal spray techniques, such as high-velocity oil fuel (HVOF), arc spray, plasma spraying, and detonation spray coating $[3,4]$. The spray and fuse thermal spray process has important advantages compared to other thermal spray techniques due to the ease of production of the coatings, the wide variety of geometries and surfaces that can be coated, the relatively low cost of coating production, and the ease of handling of the equipment. Furthermore, coatings produced using this technique have a lower degree of porosity and high adhesion to the substrate. These coatings have been used in applications such as protection against abrasive wear for industrial tools $[5,6]$.

Some applications of the cermet coatings have been reported by some authors like Szymański et al., who found that coatings produced by thermal spray techniques have shown high resistance to corrosion and erosion in industry applications. Cavitation erosion tests were performed on coatings deposited by the $\mathrm{HBOF}$ technique according with the ASTM G32 standard, identifying sliding wear mechanisms and cavitation in coatings. Likewise, failure analysis of cermet coatings deposited by HBOF technique showed that Yttria reinforced WC-10Co4Cr coating has superior triboresistance and mechanical properties, while $\mathrm{WC}-10 \mathrm{Co} 4 \mathrm{Cr}$ coating showed good wear resistance in fly ash slurry which possesses a weak acidic nature. The mechanical properties of 
the Ni-based alloy/nano-h-BN self-lubricating composite coatings were analyzing by Zhang et al., who found that the average microhardness of the coatings was influenced by the addition of solid lubricant in the powder feedstocks [7-10].

In the present investigation, we describe the tribological behavior of Ni-based WC-Co coatings deposited via the spray and fuse technique and evaluate the tribological behavior as a function of the oxygen flux. The reports regarding the variation of the oxygen flow in thermal spray systems are extensive, and authors such as Bandgopadhyag et al. and Nylen used computer software to model the effect of the oxygen flow on the distribution of speeds and temperatures in an oxyacetylene flame. The heat power $P_{f}$ dissipated by the flame depends on the fuel/oxidant ratio and the fuel gas feed rate, $m u$; as the limiting factor in combustion is $\mathrm{mO}_{2}$, it can be said that $P_{f}$ is proportional to the oxygen flow. Therefore, the oxygen flow is a very important parameter in mechanical and tribological properties of the coatings grew via thermal spray technique; however, the reports found in the literature in this regard are poor [11-15].

\section{Experimental Setup}

Using the spray and fuse thermal spray technique, Ni-based WC-Co coatings were deposited on gray cast-iron cylindrical substrates of $41 \mathrm{~mm}$ in diameter and $4 \mathrm{~mm}$ in thickness, varying the oxygen flow in the oxyacetylene flame four times, with the objective to obtain carburizing, neutral, and oxidizing flames. The substrates were cleaned using a commercial degreasing liquid and subsequently immersed in an ultrasonic bath for 10 minutes. A commercial powder called MetaCeram was used for filler material. In the deposition process of the coatings, the gray cast iron substrate is preheated to temperatures between 500 and $600^{\circ} \mathrm{C}$, then the filler material is sprayed onto the substrate, and then this material is melted onto the substrate, forming the coating. The deposition conditions are summarized in Table 1 . The parameters of the pressure of the gases, the distance between the spraying and fuse, and the nozzle type were given by the manufaturater of MetaCeram powders.

The crystalline structure of the coatings was analyzed using the X-ray diffraction (XRD) technique. The XRD patterns were obtained with Panalytical equipment in Bragg-Brentano geometry with $\mathrm{Cu} K \alpha$ radiation of $\lambda=1.5406 \AA$ and a step of $0.02^{\circ}$. To determine the crystallographic planes of the coatings, $\mathrm{X}^{\prime}$ Pert HighScore software was used. Using scanning electron microscopy (SEM) and confocal laser microscopy, the morphology and the topographical details of the coatings were analyzed, as well as the wear tracks, in order to determine the wear mechanisms of the coatings. The chemical analyses of the coatings and the wear tracks were carried out by means of energy-dispersive X-ray spectroscopy (EDS) using a FEI Quanta 200-r equipment.

Microhardness measurements were carried out using a Knoop scale LECO micro indenter, with $300 \mathrm{~g}$ of load and $15 \mathrm{~s}$ of dwell time. The wear measurement was made using the ASTM G99-04 test, with a pin-on-disk CETR-UMT-2110 tester, working at room temperature, with a test time of
$600 \mathrm{~s}$ and $400 \mathrm{~g}$ of load using a steel ball of $838 \mathrm{HV}$ of hardness and $10 \mathrm{~mm}$ in diameter and a test speed of $10 \mathrm{~cm} / \mathrm{s}$. Additionally, we used the ASTM G-65 test under the B procedure ( $130 \mathrm{~N}$ of load and 2000 revolutions of the wheel to obtain $\sim 1436 \mathrm{~m}$ of wear distance).

\section{Results and Discussion}

3.1. XRD Analysis. In a previous investigation [16], we found that the XRD pattern that corresponds to MetaCeram powder exhibits $\mathrm{Ni}_{3} \mathrm{~B}$ and $\mathrm{Ni}$ peaks with $\mathrm{Ni}$ reflections in crystallographic planes (111), (200), (220), (311), and (222), according to the X'Pert HighScore card, with reference code: 03-065-2865. WC (hex) (001), (100), and (101), and $\mathrm{W}_{2} \mathrm{C}$ and metallic $\mathrm{W}$ peaks were detected, due to the decarburization process of the WC particles, according to the cards with reference code 00-051-0939 and 01-070-2633. This crystallographic structure of the MetaCeram was reproduced in the coatings produced under different oxygen flow conditions. Additionally, in the coatings, a $\mathrm{B}_{2} \mathrm{O}_{3}$ peak, with reflections in crystallographic plane (310), appears in the patterns. The crystallite size was determined using the Williamson-Hall method.

3.2. Microhardness. According to Paneto et al. [17], in order to calculate the theoretical hardness $\left(\mathrm{HV}_{0}\right)$ of composite materials, such as MetaCeram coatings, it is necessary to consider the molar fractions of the deposited constituents multiplied by their respective theoretical hardness. For MetaCeram, the main elements of the flux powder are taken as $\mathrm{wt} \%$, which are in the following order: $\mathrm{Ni}$ at $44 \%, \mathrm{WC} / \mathrm{Co}$ at $40 \%$, and $\mathrm{Cr}$ at $9.3 \%$. To calculate the theoretical hardness, the relationship used is,

$$
\mathrm{HV}_{0}=\left(A 630_{\mathrm{HV}}\right)+\left(B 2050_{\mathrm{HV}}\right)+\left(C 90_{\mathrm{HV}}\right) \text {, }
$$

where $\mathrm{A}$ is the molar fraction of $\mathrm{Ni}, \mathrm{B}$ is the molar fraction of WC, $\mathrm{C}$ is the molar fraction of $\mathrm{Cr}, 630 \mathrm{HV}$ is the theoretical hardness of $100 \%$ dense $\mathrm{Ni}, 2050 \mathrm{HV}$ is the theoretical hardness of $100 \%$ dense WC/Co, and finally $90 \mathrm{HV}$ is the theoretical hardness of $100 \%$ dense Cr. Using equation (1), the theoretical hardness of the MetaCeram coatings was calculated obtaining a value of $1105.57 \mathrm{HV} 10850 \mathrm{MPa}$. This value is very close to the average microhardness values registered for the coatings in Table 2 for the coatings deposited at different oxygen fluxes. These values are the result of the average of the hardness taken on the diametric lines of the surface of the coatings, with three control samples for each deposit.

Figure 1 shows the variation in the microhardness with the crystallite size in the metallic Ni matrix and the WC/Co particles. The graph shows that coatings with a crystallite size of $50 \mathrm{~nm}$ in the Ni matrix and $67 \mathrm{~nm}$ in the WC/Co matrix reach a maximum value of the microhardness. Additionally, a noticeable decrease in microhardness is also recorded for crystallite values close to $10 \mathrm{~nm}$, which is in accordance with the Hall-Petch theory which indicates that the yield stress and hence the hardness are related with the inverse square root of crystallite size $[18,19]$. Moreover, Sriraman et al. [20] report 
TABle 1: Deposition conditions of the MetaCeram coatings.

\begin{tabular}{|c|c|c|c|c|}
\hline Brand of torch & \multicolumn{4}{|c|}{ SuperJet Eutalloy } \\
\hline $\mathrm{O}_{2}$ pressure $(\mathrm{psi})$ & \multicolumn{4}{|c|}{$39(268.896 \mathrm{kPa})$} \\
\hline $\mathrm{C}_{2} \mathrm{H}_{2}$ pressure $(\mathrm{psi})$ & \multicolumn{4}{|c|}{$7(48.2633 \mathrm{kPa})$} \\
\hline $\mathrm{O}_{2}$ flow $(\mathrm{SCFH})$ & 11.04 & 12.88 & 14.72 & 16.56 \\
\hline $\mathrm{C}_{2} \mathrm{H}_{2}$ flow (SCFH) & \multicolumn{4}{|c|}{14.64} \\
\hline Powder code & \multicolumn{4}{|c|}{ MetaCeram 23075} \\
\hline Powder composition & \multicolumn{4}{|c|}{$44 \mathrm{Ni}, 40 \mathrm{WC} / \mathrm{Co}, 9.3 \mathrm{Cr}, 1.9 \mathrm{~B}, 2.1 \mathrm{Fe}, 2.3 \mathrm{Si}, 0.4 \mathrm{C}$. } \\
\hline Spraying-fusion distance & \multicolumn{4}{|c|}{$150-20 \mathrm{~mm}$} \\
\hline Nozzle & \multicolumn{4}{|c|}{ B2 } \\
\hline
\end{tabular}

TABLE 2: Average values of surface microhardness of MetaCeram coatings deposited at different oxygen fluxes.

\begin{tabular}{lcc}
\hline MetaCeram samples & Average microhardness $(\mathrm{MPa})$ & Thickness $(\mu \mathrm{m})$ \\
\hline Steel ball & $8218 \pm 94,31$ & - \\
Substrate & $347.48 \pm 54$ & - \\
MetaCeram (theoretical value) & $10850^{*}$ & $228.41 \pm 6.42$ \\
$(11.04$ SCFH) & $9448.09 \pm 32.15$ & $230.53 \pm 4.14$ \\
$(12.88$ SCFH $)$ & $10470.64 \pm 61.23$ & $270.14 \pm 9.03$ \\
$(14.72$ SCFH $)$ & $10092.27 \pm 12.95$ & $250.16 \pm 2.97$ \\
$(16.56$ SCFH $)$ & $9010.88 \pm 67.65$ & \\
\hline
\end{tabular}

* The microhardness values summarized in Table 2 were made on the surface of the coatings since other values of the microhardness were made on the transversal section.

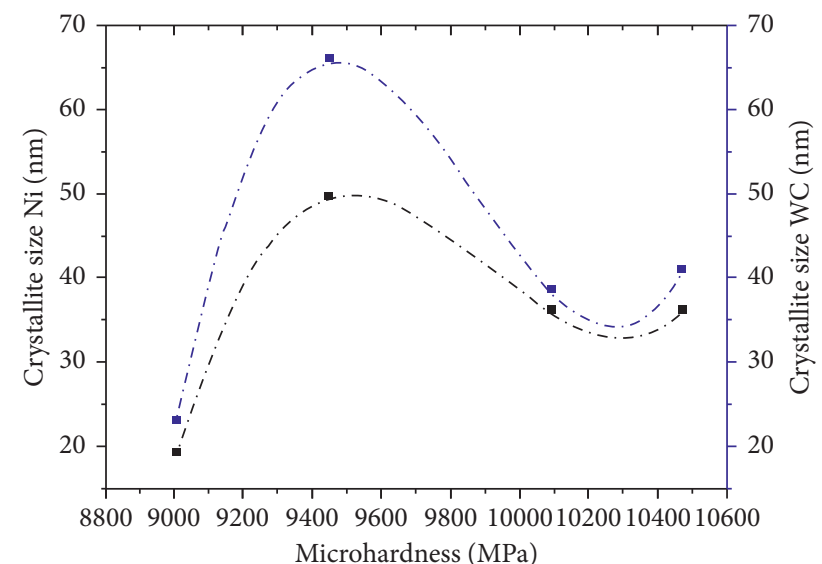

FIgure 1: Crystallite sizes of Ni matrix and WC-Co particles as a function of microhardness.

that refinement of the crystallite size of $\mathrm{Ni} \mathrm{W}$ alloys results in an increase in the hardness of the material. As the microstructure of the material is refined, the elastic limit or the hardness of the material increases and then decreases, after reaching a maximum yield stress threshold. Several studies have established this threshold at values between 10 and $40 \mathrm{~nm}$. The effect of crystallite size on the tensile strength can be analyzed from the theory of dislocation; thus, the plastic deformation of the material must be able to overcome the maximum stress, which increases the density of the dislocations. A small crystallite size generates a greater number of borders between crystals, and this hinders the movement of the dislocations, and the maximum tensile stress in a plastic deformation is strongly influenced by the average size of the crystallite and the morphology of the particle.

The reduction in microhardness is also highly influenced by porosity. The porosity index was calculated through the results obtained from the characterization carried out using the potentiodynamic polarization technique on the substrate and the coatings in a previous paper, and the average error in the porosity measurement was $0.021 \%$ [16]. Figure 2 shows the cross section of the MetaCeram coatings; in this figure, the pores of the coatings are clearly appreciated. Figure 3 shows the variation of the microhardness as a function of the porosity. It is clear that large porosity values result in a decrease in the hardness of the deposits. This behavior can be explained since the load indenter did not find material in the porous places.

3.3. Scratch Test. Figure 4 shows the tracks for the scratch tests performed on the MetaCeram coatings for a load of $15 \mathrm{~N}$. The area of the cones was obtained via optical microscopy with image analyzer. The scratch resistance values obtained under the application of ISO/WD 27307 are summarized in Table 3. The coefficient of variation $(\mathrm{Vr})$ is determined according to,

$$
V_{r}=\frac{\sigma}{\mu} * 100 \%
$$

where $\rho$ represents the standard deviation and $\mu$ is the average value of the cone area $[21,22]$.

In these coatings, the $5 \mathrm{~N}$ load did not generate a detectable scratch trace, due to their high hardness, while with a load of $10 \mathrm{~N}$, although it was possible to appreciate the scratch tracks and the formation of cones in the substratecoating interface and in the superficial zone, the propagation of cracks through the scratch pattern was not clearly seen. For the scratch tests performed with $15 \mathrm{~N}$, the formation of a cone at the substrate-coating interface as well as the surface of the cone was much clearer. These formations could suggest that the failure in these coatings is both adhesive and cohesive. However, in the absence of clear cracking of the 


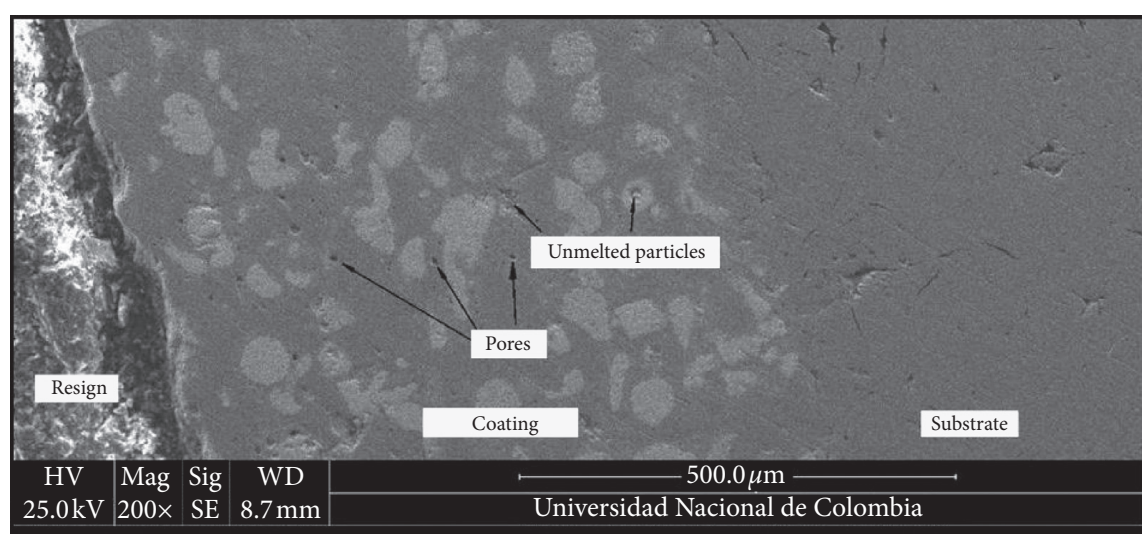

Figure 2: MetaCeram coatings' cross section.

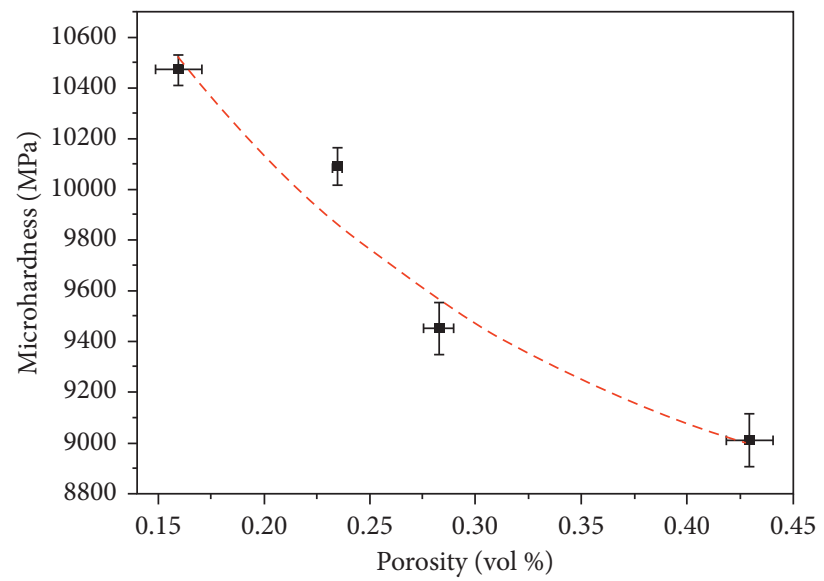

Figure 3: Microhardness vs porosity of MetaCeram coatings.

substrate-coating interface, it can also be assumed that the formation of the cone in the adhesive zone could be a product of the high hardness difference between the gray cast iron substrate and the coating, which can cause an abrupt change in the degree of penetration of the indenter when passing from substrate to coating.

In the cohesive failure zone, the coating is separated by means of the scratch test for the $15 \mathrm{~N}$ load, and the release of WC/Co particles or nonmolten particles was detected using the scratch test, which demonstrates that the carbide particles do not completely melt with the metallic Ni matrix of the coating. The area of the cone was shown to be related to the degree of porosity of the coatings: the coatings with a higher degree of porosity recorded higher values of the area of the cone of cohesive failure.

3.4. Pin-on-Disk Wear Test. Figure 5 shows the friction coefficient (COF) curves for the MetaCeram coatings deposited under different oxygen flow conditions. The COF of the coatings was obtained from the stable area of the graphs. By means of optical microscopy using image analyzer, the average width of the wear tracks was obtained, in order to calculate the worn volume and the wear coefficient. Table 4 records the parameters of the pin-on-disk test carried out on the MetaCeram coatings. The worn volume and the wear coefficient were calculated according to equations (3) and (4), respectively. The worn volume calculation indicates that the coating did not exhibit significant wear since wear occurs mainly on the pin because the average hardness of the coating is greater than that of the pin. This can be seen in Figure 6, which was taken with confocal laser microscopy on the wear track.

$$
V_{w}=\frac{\pi D^{4}}{64 d}
$$

where $D$ represents the diameter of the pin and $d$ is the diameter of the wear track.

$$
K=\frac{V_{w}\left(\mathrm{~mm}^{3}\right)}{L(N) d(m m)},
$$

where $V_{w}$ is the worn volume and $L$ is the load.

In general, the coatings of MetaCeram showed that the wear coefficient $\mathrm{K}$ and the COF change appreciably at higher oxygen flux in the flame. This is probably due to the fact that the products with a higher degree of hardness, such as WC/ Co, aggregate in the Ni matrix, which results in less effective contact friction. The results obtained in the adhesive wear tests are in agreement with previous studies. Authors such as Torgerson et al. [23] report the formation of $\mathrm{NiO}$ layers in nickel-based coatings deposited via cold thermal spraying. These authors found that the formation of $\mathrm{NiO}$ layers reduces the coefficient of friction. Likewise, WC particles 


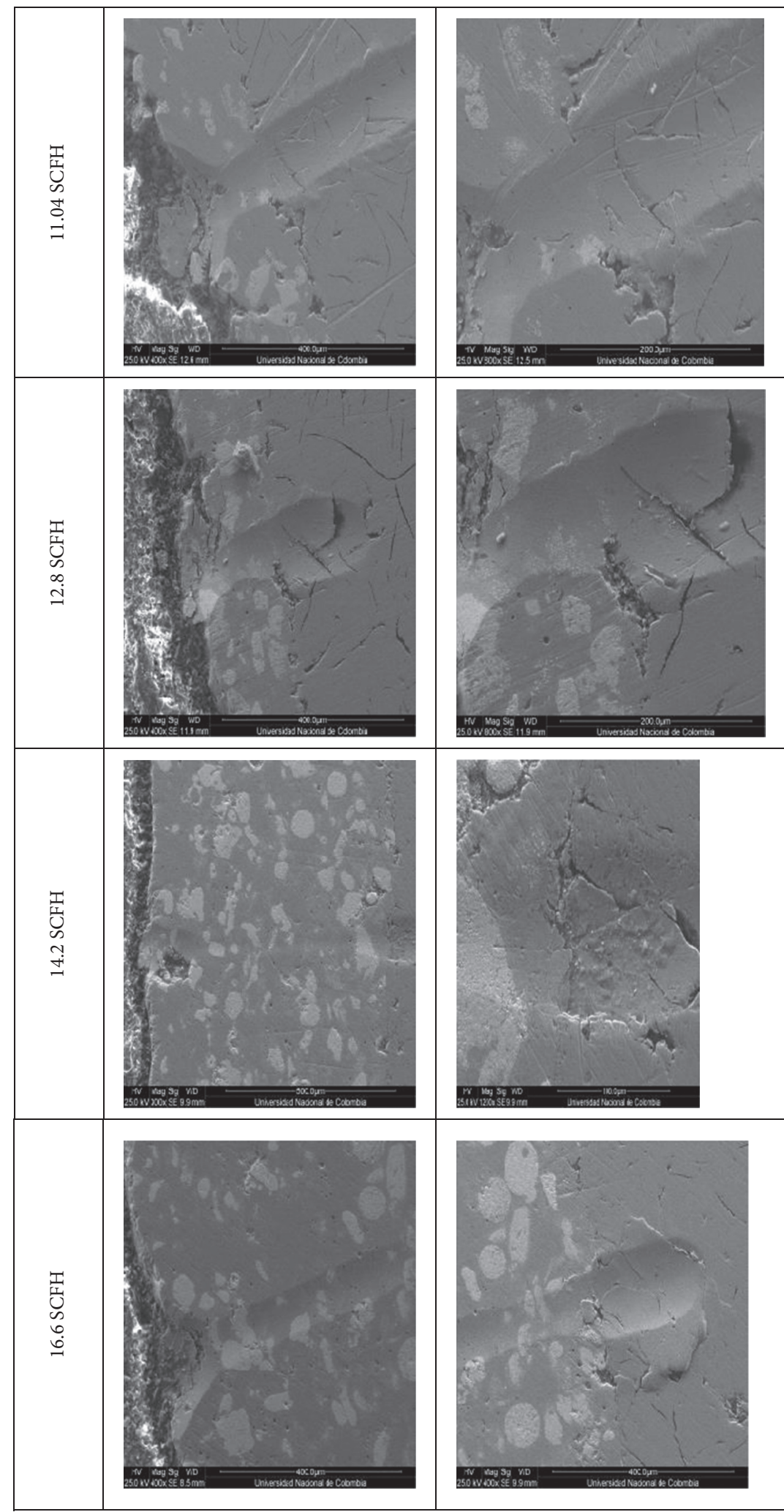

Figure 4: Scratch test of MetaCeram coatings.

provided resistance to thermal softening and helped to improve the wear resistance at elevated temperatures.

Figure 7 shows the deterioration undergone by MetaCeram coatings in the course of the pin-on-disk wear test.
The images do not reveal furrows of abrasive wear; this confirms that the wear mechanism for these coatings is mainly due to adhesive wear produced by the oxides, evidenced by the XRD study and possible oxides formed during 
TABLE 3: Average results of scratch resistance of MetaCeram coatings.

\begin{tabular}{|c|c|c|c|c|c|}
\hline Coating & $\mathrm{O}_{2}$ flow $(\mathrm{SCFH})$ & Scratch test load (N) & Projected cone area $A_{c}\left(\mu \mathrm{m}^{2}\right)$ & Variation coefficient Vr (\%) & Failure \\
\hline \multirow{12}{*}{ MetaCeram } & \multirow{3}{*}{11.04} & 5 & - & - & - \\
\hline & & 10 & 9089.8 & 17.25 & Adhesive/cohesive \\
\hline & & 15 & 11284 & 18.41 & Adhesive/cohesive \\
\hline & \multirow{3}{*}{12.88} & 5 & - & - & - \\
\hline & & 10 & 3224.34 & 20.05 & Adhesive/cohesive \\
\hline & & 15 & 6280.75 & 19.16 & Adhesive/cohesive \\
\hline & \multirow{3}{*}{14.72} & 5 & - & - & - \\
\hline & & 10 & 1685.4 & 18.21 & Adhesive/cohesive \\
\hline & & 15 & 1870.26 & 20.84 & Adhesive/cohesive \\
\hline & \multirow{3}{*}{16.56} & 5 & - & - & - \\
\hline & & 10 & 8282 & 19.45 & Adhesive/cohesive \\
\hline & & 15 & 17289 & 18.37 & Adhesive/cohesive \\
\hline
\end{tabular}

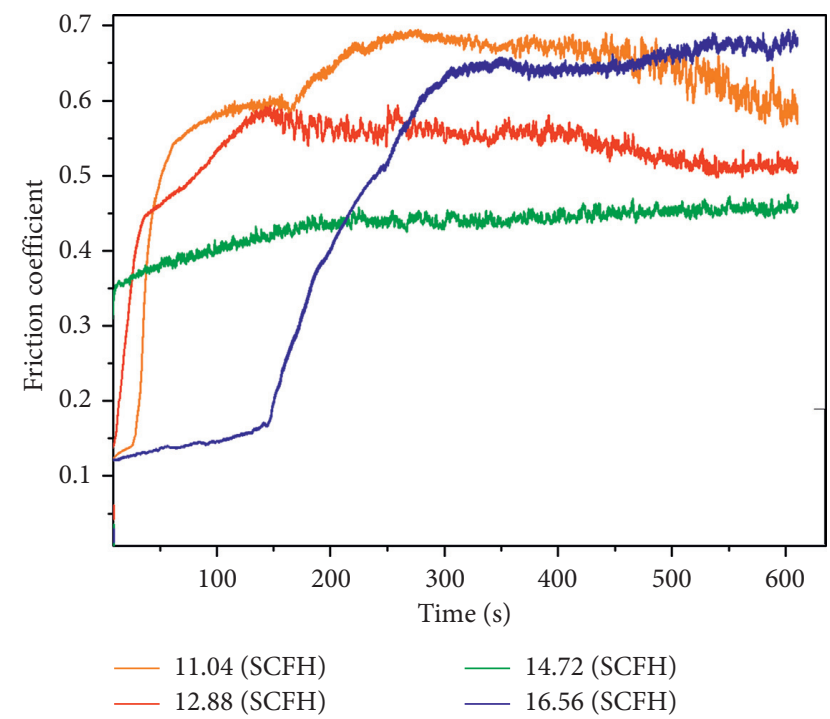

Figure 5: Coefficient of friction (COF) as a function of the time curves of MetaCeram coatings.

TABle 4: Pin-on-disk test parameters of MetaCeram coatings.

\begin{tabular}{lccc}
\hline MetaCeram & VW (MM3) & $K$ & COF \\
\hline (11.04 SCFH) & $0.032 \pm 0.061$ & 8.03 E- $8 \pm 0,11$ & $0.662 \pm 0.022$ \\
$(12.88$ SCFH) & $0.016 \pm 0.037$ & 1.05 E- $8 \pm 0,04$ & $0.621 \pm 0.013$ \\
$(14.72$ SCFH) & $0.025 \pm 0.032$ & 5,36 E- $8 \pm 0,23$ & $0.423 \pm 0.046$ \\
$(16.56$ SCFH) & $0.054 \pm 0.071$ & 8.93 E- $8 \pm 0,07$ & $0.675 \pm 0.036$ \\
\hline
\end{tabular}

the wear test. The images also show that the WC particles do not undergo significant deterioration after the wear test; on the contrary, they act as accumulation points for worn material, which prevents the abrasive wear mechanism. Some areas of the coatings showed microcracks at points with defects such as nonmolten particles or pores on the wear track.

The wear mechanism evident in the pink-on-disk test showed that the points, the contact between coating surface and wear ball (contact points), are generate peaks or roughness own of the coatings deposited at high oxygen pressure (16.56 SCFH). The points of contact are broken and regenerated as the test develops.

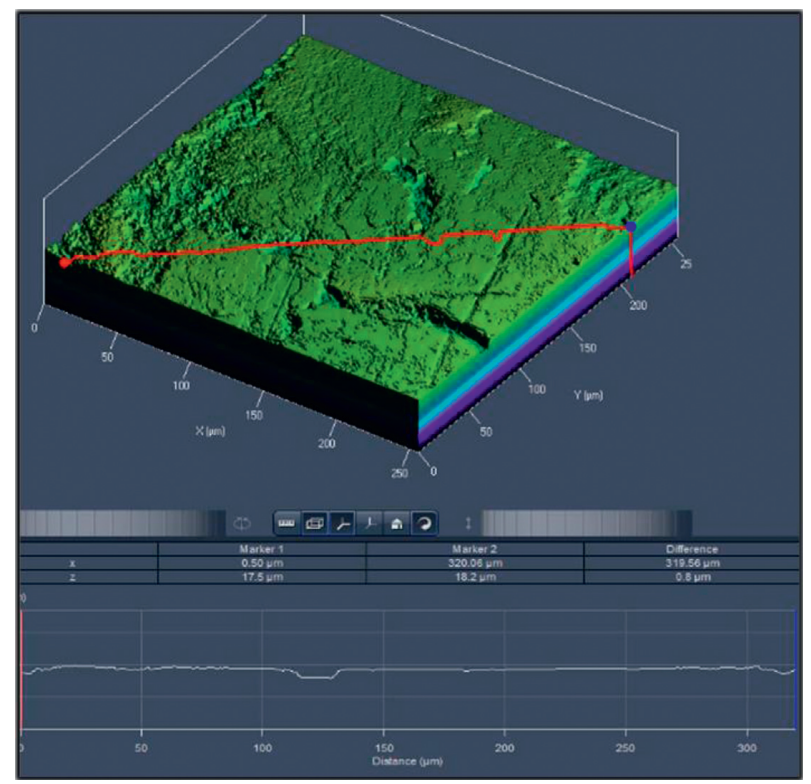

FIGURE 6: Pin-on-disk wear tracks of MetaCeram coatings obtained by confocal microscopy.

The behavior of the wear rate as a function of the microhardness is illustrated in Figure 8. In the figure, it is evident that the wear coefficient increases with the microhardness.

3.5. Abrasive Wear Test. The abrasive wear tests of the gray cast substrates and the MetaCeram coatings were carried out following procedure B of the ASTM G-65 rubber-wheel test standard, which specifies a load of $130 \mathrm{~N}$ with 200 -wheel revolutions, which generates $1436 \mathrm{~m}$ of wear distance using Ottawa sand as abrasive. Using Archard's equation (equation (5)), the wear coefficient was calculated. For this, it was necessary to determine the volume of worn material, which was obtained using equation (6).

$$
\begin{aligned}
& V=\frac{K * L * x}{H}, \\
& V=\frac{m_{i}-m_{f}}{\sigma}(1000),
\end{aligned}
$$




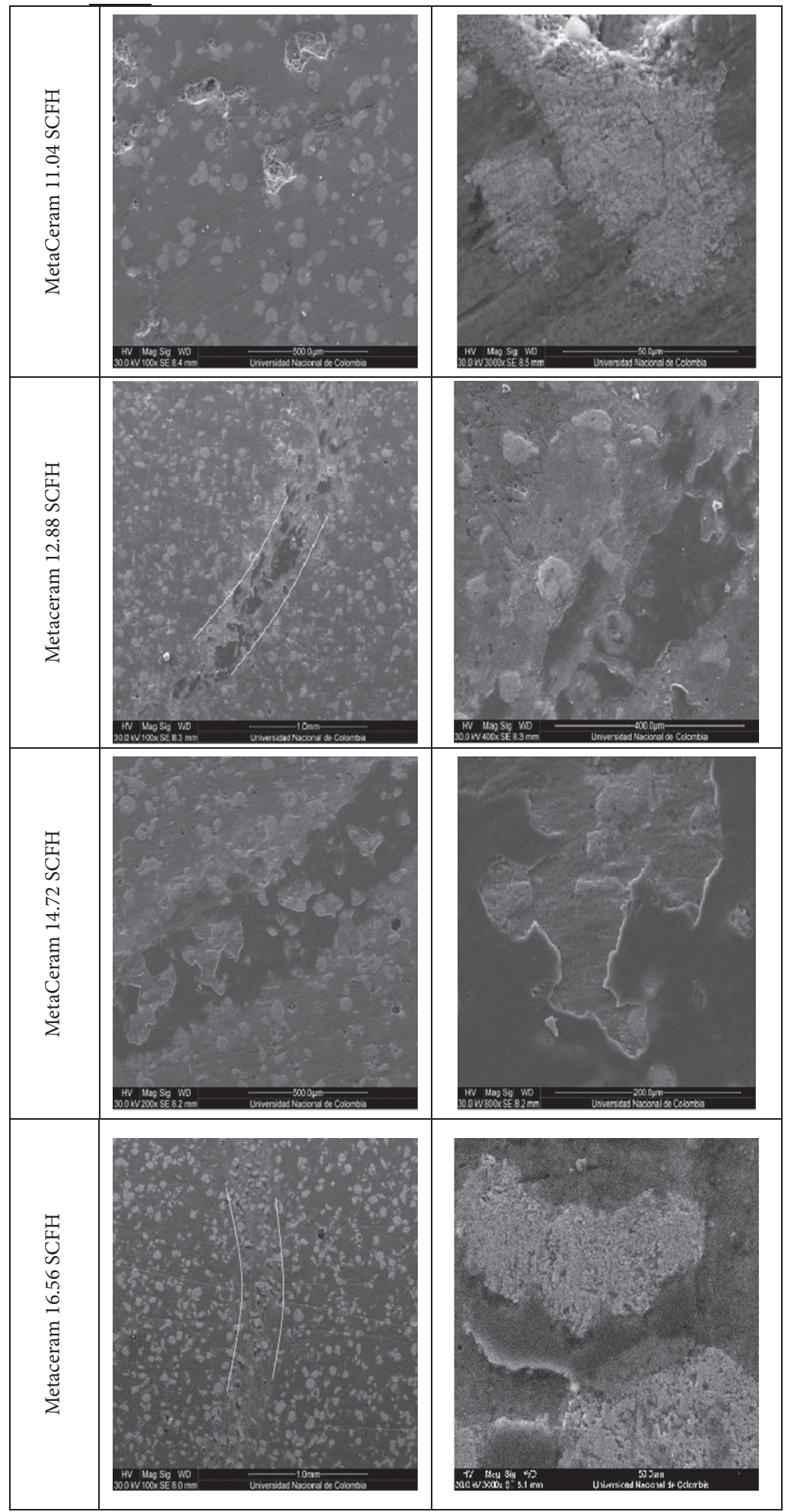

Figure 7: SEM micrographs of pin-on-disk wear tracks of MetaCeram coatings.

where $K$ is the wear coefficient, $\mathrm{V}\left(\mathrm{mm}^{3}\right)$ is the wear volume of the softest material, $\mathrm{H}(\mathrm{GPa})$ is the hardness of the sample, $\mathrm{L}(\mathrm{N})$ is the force exerted on the specimen, $x(m)$ is the linear abrasion value, and $\mathrm{mi}$ and $\mathrm{mf}$ represent, respectively, the initial and final values of the mass of the samples analyzed.
Figure 9 shows the wear tracks of the MetaCeram coatings. It is possible to see the deterioration undergone by these coatings due to the abrasive wear tests. The type of damage recorded was similar for all coatings, independent of the oxygen flow at which they were deposited. In the graphs, 


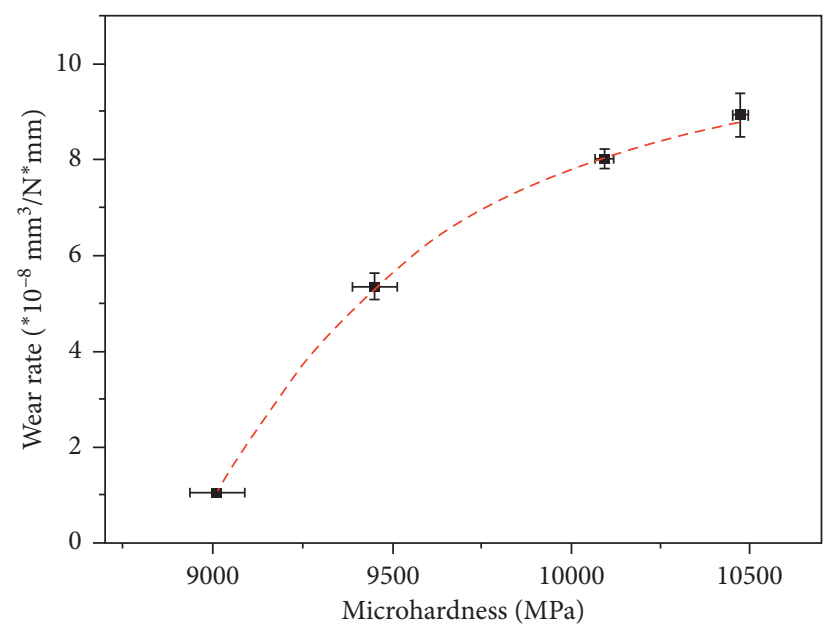

Figure 8: Microhardness vs wear coefficient of MetaCeram coatings.

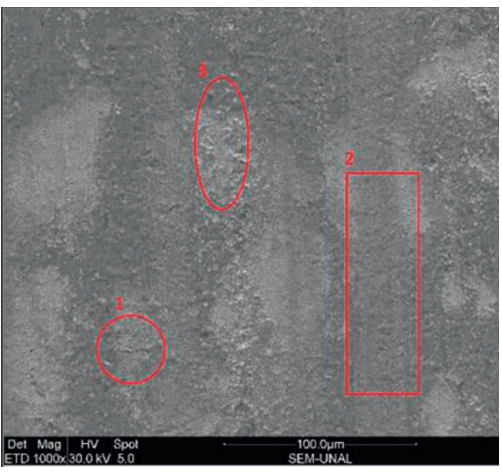

(a)

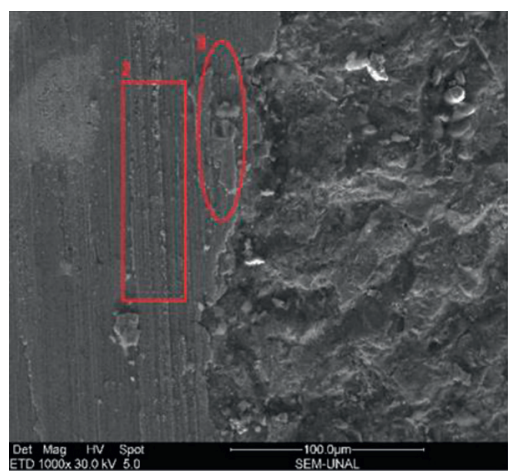

(b)

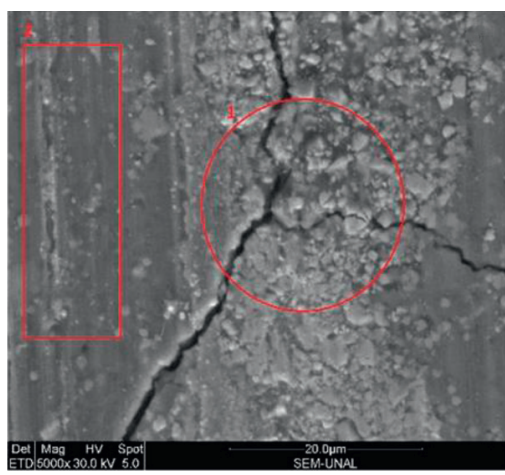

(c)

FIGURE 9: SEM micrograph of wear traces for MetaCeram coatings.

the presence of shallow grooves, a product of a microplowing mechanism, is evident. These furrows are produced by the displacement and later accumulation of the material in front of the abrasive particles. The particles of WC/Co in the metallic Ni matrix of the MetaCeram coating act as accumulators of the detached material and even of the abrasive. The accumulation of this material in specific zones can cause stress concentrations that lead to plastic deformation of the ductile areas of the coating, which are those where the concentration of $\mathrm{Ni}$ is predominant. The mechanism of microplowing is recorded in the graphs as deterioration zones 1 and 2 , which are highlighted by circumference and rectangles; likewise, the zone where there is plastic deformation is identified with the number 3 and is highlighted with an oval.

The graphs also record the formation of microcracks, mainly in areas rich in WC/Co. This is due to the fragility of the WC/Co particles and the high surface tension caused by sliding of abrasive (sand) with these particles, which produce regions of acumulation, the abrasive and detached materials, that increase the net pressure on the coating-substrate interphase. Figure 9(c) shows how the fracture occurs between the individual grains that make up the regions rich in $\mathrm{WC}$ /
Co, following a line of fracture that borders these individual structures, which allows us to infer a cohesion failure in them. It can also be seen how the fracture of these areas propagates to the metal matrix of the coating. These results are in agreement with those reported by St-Georges [24], who found a mechanism of attrition by removal of the metallic binder matrix in $\mathrm{Ni}-\mathrm{Cr}+\mathrm{WC}$ coatings, also recording little evidence of fragmentation of WC particles. Likewise, Liyanage et al. [25] recorded the phenomenon of crack propagation for WC agglomerates in Ni-WC coatings. The geometry of the cracking reported by these authors coincides with that reported in the present investigation.

Table 5 records the abrasive wear parameters obtained for MetaCeram coatings. The results show a lower degree of wear than the gray cast substrate. This is due to the presence of the WC/Co system in the metallic $\mathrm{Ni}$ matrix in the MetaCeram coatings. Both the wear rate and the wear coefficient recorded showed a close relationship with the hardness and porosity of the coatings. Figure 10 shows the variation of the microhardness as a function of the wear rate and the degree of porosity of the MetaCeram coatings.

This graph shows a clear, decreasing relationship between the microhardness and the wear rate. These results 
TABLe 5: Gray cast iron substrate and MetaCeram coatings' adhesive wear parameters.

\begin{tabular}{lcccc}
\hline Sample & Mass loss $(\mathrm{g})$ & Worn volume $\left(\mathrm{mm}^{3}\right)$ & Wear coefficient $K\left(\times 10^{-4}\right)$ & Wear $\mathrm{rate}^{W}\left(\times 10^{-5} \mathrm{~mm} / \mathrm{Nm}\right)$ \\
\hline MetaCeram (11.04 SCFH) & $0.1238 \pm 0,0048$ & 13.601 & 3,441 & 3.6420 \\
MetaCeram (12.88 SCFH) & $0.0410 \pm 0,0037$ & 4.5064 & 1.218 & 1.2067 \\
MetaCeram (14.72 SCFH) & $0.0793 \pm 0,0094$ & 8.7133 & 2.443 & 2.3332 \\
MetaCeram (16.56 SCFH) & $0.1967 \pm 0,0081$ & 21.617 & 5.216 & 5.7885 \\
\hline
\end{tabular}

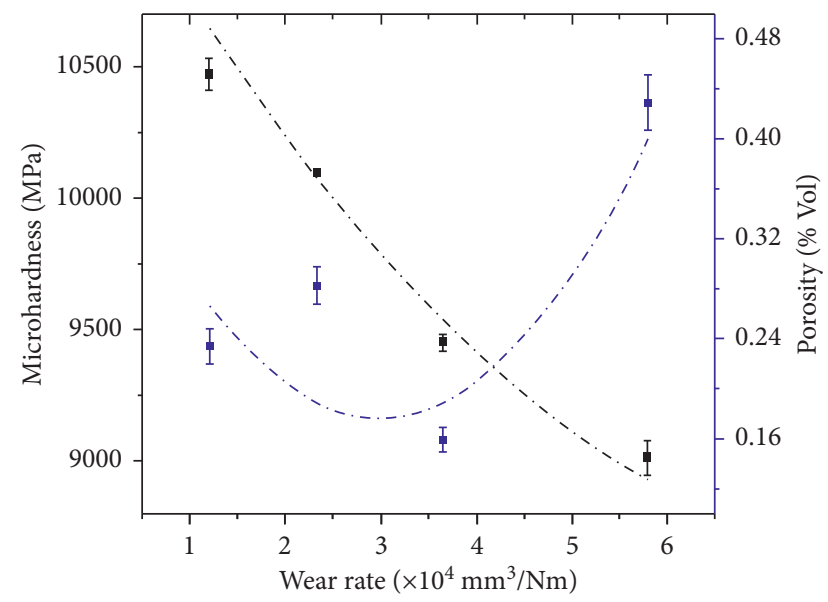

FIGURE 10: Microhardness and porosity of MetaCeram coatings as a function of wear rate.

agree with what was reported by Liyanage et al., who analyzed the abrasive wear resistance of Ni-WC coatings [25]. These authors found a close relationship between the microhardness and the wear resistance of the coatings; however, it is important to note that the wear rate is related to both the overall hardness of the coatings, which is influenced by the average WC particle content in them and the distribution of these particles on the surface. The rate of wear increases drastically when the mean free path between the WC particles exceeds $114 \mu \mathrm{m}$. This is because a greater distance between WC particles produces a significant fraction of the metallic Ni matrix on the surface of the wear track in direct contact with abrasive sand particles [26-28].

On the other hand, in the figure possibly a relationship between the wear rate and the porosity is not established, since the values of the wear rate only show a notable change in coatings that have $0.42 \%$ porosity [29-31].

\section{Conclusions}

MetaCeram coatings deposited as a function of the oxygen content of the flame on gray cast iron via spray fuse technique show the following characteristics.

(i) The coatings exhibit values of microhardness close to the theoretical values, and the coatings deposited at a high rate of flow of the oxygen in the flame exhibit the lowest microhardness.

(ii) The lowest oxygen content in the flame produced a grain size of $10 \mathrm{~nm}$, which results in low microhardness in the coatings; the coatings deposited with flows of 14 and $16 \mathrm{SCFH}$ of oxygen exhibited higher microhardness. (iii) The porosity of the coatings increases with the oxygen flow, which produces a decrease in their microhardness.

(iv) For all flows of oxygen used in the deposit of the coatings, cohesion and adhesion wear mechanisms were simultaneously present.

(v) In the stable zone of the coatings, the lowest COF was obtained in the coatings deposited with 14 SCFH oxygen flow.

(vi) The decarburization process negatively affected the mechanical and tribological properties of MetaCeram coatings, both due to a reduction in hardness due to the degradation of $\mathrm{WC}$ in $\mathrm{W}_{2} \mathrm{C}$ and metallic $\mathrm{W}$, as well as the increase in porosity due to the Kirkendall effect.

(vii) The wear tests showed wear mechanisms due to adhesion, abrasion, and oxide formation, mainly. These mechanisms respond directly to the ductile characteristics of nickel as the metallic matrix of the coatings and to the fragility of WC/Co ceramic, which is the main aggregate in the MetaCeram coating. In this work, it was possible to determine the relationship of crystallographic properties of MetaCeram coatings, with their wear rate. Likewise, the influence of the topography of the coatings with the wear resistance was established.

\section{Data Availability}

The data used to support the findings of this study are included within the article.

\section{Conflicts of Interest}

The authors declare that they have no conflicts of interest.

\section{Acknowledgments}

The authors would like to thank COLCIENCIAS for providing financial support to the project "Caracterización estructural y química mediante haces de iones de recubrimientos nanoestructurados con aplicaciones tecnológicas" and Universidad Nacional de Colombia.

\section{References}

[1] S. Purkayastha and D. K. Dwivedi, "Effect of $\mathrm{CeO} 2$ on the friction and sliding wear performance of $\mathrm{Ni} / \mathrm{WC}$ coatings," in Proceedings of the International Conference on Advances in Electrical and Mechanical Engineering (ICAEME'2012), pp. 18-19, Phuket, Thailand, 2012. 
[2] Z. Geng, H. Huang, B. Lu, S. Wu, and G. Shi, "Tribological behaviour of low-pressure plasma sprayed WC-Co coatings at elevated temperatures," Industrial Lubrication and Tribology, vol. 71, no. 2, pp. 258-266, 2019.

[3] S. Al-Mutairi, M. S. J. Hashmi, and B. S. Yibas, "Microstructural characterization of $\mathrm{HVOF} /$ plasma thermal spray of micro/nanoWC-12\%Co powders"' Surface and Coating Technology, vol. 264, pp. 175-186, 2015.

[4] G. Bolelli, A. Candeli, H. Koivuluoto et al., "Microstructurebased thermo-mechanical modelling of thermal spray coatings," Materials \& Design, vol. 73, pp. 20-34, 2015.

[5] M. H. Abd Malek, N. H. Saad, S. K. Abas, N. R. Nik Roselina, and N. M. Shah, "Performance and microstructure analysis of $99.5 \%$ aluminum coating by thermal arc spray technique," Procedia Engineering, vol. 68, pp. 558-565, 2013.

[6] X. Yang, X. Li, Q. Yang, H. Wei, X. Fu, and W. Li, "Effects of WC on microstructure and corrosion resistance of directional structure Ni60 coatings," Surface and Coatings Technology, vol. 385, Article ID 125359, 2020.

[7] X. Zhang, L. Zhang, and Z. Huang, "Microstructure characteristics and properties of HVOF sprayed Ni-based alloy nano-h-BN self-lubricating composite coatings," Advances in Tribology, vol. 2015, Article ID 621278, 6 pages, 2015.

[8] K. Szymański, H. Adam, G. Moskal, and M. Hanna, “Thermally sprayed coatings resistant to erosion and corrosion for power plant boilers - a review," Surface and Coatings Technology, vol. 268, pp. 153-164, 2015.

[9] M. Szala, M. Walczak, L. Łatka, K. Gancarczyk, and D. Özkan, "Cavitation erosion and sliding wear of MCrAlY and NiCrMo coatings deposited by HVOF thermal spraying," Advances in Materials Science, vol. 20, no. 64, 2020.

[10] J. Singh, S. Kumar, and S. K. Mohapatra, "Tribological performance of Yttrium (III) and Zirconium (IV) ceramics reinforced WC-10Co4Cr cermet powder HVOF thermally sprayed on X2CrNiMo-17-12-2 steel," Ceramics International, vol. 45, no. 17, pp. 23126-23142, 2019.

[11] PiR. B. Se L. Fauchais, J. V. R. Heberlein, and M. I. Boulos, Thermal Spray Fundamentals, pp. 20-22, Universidad Complutense de Madrid, Madrid, España, 2011.

[12] J. Wigren, O. Hansson, P. Gougeon, and C. Moreau, "On-line diagnostics of traditional flame spraying as a tool to increasereproducibility," in Berndt CC, ProcEDSings of national thermal spray conference, pp. 675-681, ASM International, Materials Park, OH, USA, October 1996.

[13] P. Nyle'n and R. Bandyopadhyay, "A computational fluid dynamic analysis of gas and particle flow in flame spraying"” in Proceedings of the Berndt CC, Thermal spray: surface engineering via applied research, pp. 237-244, ASM International, Materials Park, OH, USA, December 2003.

[14] Diaz, Model of Plume Flowfield from Oxy-Acetylene Torch American Institute of Aeronautics and Astronautics, 55th AIAA Aerospace Sciences Meeting, Austin, TX, 2017.

[15] Y. Kawaguchi, F. Miyazaki, M. Yamasaki, Y. Yamagata, N. Kobayashi, and K. Muraoka, "Coating qualities deposited using three different thermal spray technologies in relation with temperatures and velocities of spray droplets," Coatings, vol. 7, pp. 1-10, 2017.

[16] H. Jiménez, J. J. Olaya, J. E. Alfonso, C. A. Pineda-Vargas, and C. A. Pineda-Vargas, "Corrosion resistance of Ni-based coatings deposited by spray and fuse technique varying oxygen flow," Surface and Coatings Technology, vol. 321, pp. 341-349, 2017.

[17] F. J. Paneto, J. L. Pereira, J. O. Lima et al., "Effect of porosity on hardness of Al2O3-Y3Al5O12 ceramic composite,"
International Journal of Refractory Metals and Hard Materials, vol. 48, pp. 365-368, 2015.

[18] M. H. Allahyarzadeh, M. Aliofkhazraei, A. S. Rouhaghdam, H. Alimadadi, and V. Torabinejad, "Mechanical properties and load bearing capability of nanocrystalline nickel-tungsten multilayered coatings," Surface and Coatings Technology, vol. 386, Article ID 125472, 2020.

[19] W. Xu and L. P. Dávila, "Tensile nanomechanics and the HallPetch effect in nanocrystalline aluminium," Materials Science and Engineering: A, vol. 710, pp. 413-418, 2018.

[20] K. R. Sriraman, S. Ganesh Sundara Raman, and S. K. Seshadri, "Influence of crystallite size on the hardness and fatigue life of steel samples coated with electrodeposited nanocrystalline Ni-W alloys," Materials Letters, vol. 61, pp. 715-718, 2017.

[21] A. Vencl, S. Arostegui, G. Favaro et al., "Evaluation of adhesion/cohesion bond strength of the thick plasma spray coatings by scratch testing on coatings cross-sections," Tribology International, vol. 44, no. 11, pp. 1281-1288, 2011.

[22] H. Koiprasert, S. Thaiwatthana, and P. Niranatlumpong, "Effect of resin supporter on cross-sectional scratch testing of plasma sprayed thermal barrier coating," Chiang Mai Journal of Science, vol. 44, no. 3, pp. 1073-1082, 2017.

[23] T. B. Torgerson, M. D. Harris, S. A. Alidokht et al., "Room and elevated temperature sliding wear behavior of cold sprayed Ni-WC composite coatings," Surface and Coatings Technology, vol. 350, pp. 136-145, 2018.

[24] L. St-Georges, "Development and characterization of composite Ni-Cr + WC laser cladding," Wear, vol. 263, no. 6, pp. 562-566, 2007.

[25] T. Liyanage, G. Fisher, and A. P. Gerlich, "Microstructures and abrasive wear performance of PTAW deposited Ni-WC overlays using different Ni-alloy chemistries," Wear, vol. 275, pp. 345-354, 2012.

[26] K. Van Acker, D. Vanhoyweghen, R. Persoons, and J. Vangrunderbeek, "Influence of tungsten carbide particle size and distribution on the wear resistance of laser clad WC/ Ni coatings," Wear, vol. 258, pp. 194-202, 2015.

[27] A. Sima, A.S. Yue, and R. Richard, "Chromik, Effect of WC morphology on dry sliding wear behavior of cold-sprayed $\mathrm{Ni}$ WC composite coatings," Surface and Coatings Technology, vol. 357, pp. 849-863, 2019.

[28] M. Erfanmanesh, R. Shoja-Razavi, H. Abdollah-Pour, H. Mohammadian-Semnani, M. Barekat, and S. H. Hashemi, "Friction and wear behavior of laser cladded WC-Co and Ni/ WC-Co deposits at high temperature," International Journal of Refractory Metals and Hard Materials, vol. 81, pp. 137-148, 2019.

[29] I. Farías, L. Olmos, O. Jiménez, M. Flores, A. Bream, and J. Vleugels, "Wear modes in open porosity titanium matrix composites with $\mathrm{TiC}$ addition processed by spark plasma sintering," Transactions of Nonferrous Metals Society of China, vol. 29, no. 8, pp. 1653-1664, 2019.

[30] H. S. Xu and Q. Dong, "Friction and wear behavior of WC-Ni coatings HVOF sprayed on duplex stainless steel," in Proceedings of the 8th Global Conference on Materials Science and Engineering (CMSE2019), pp. 12-15, Sanya, China, November 2019.

[31] M. Jalali Azizpour and M. Tolouei-Rad, "The effect of spraying temperature on the corrosion and wear behavior of HVOF thermal sprayed WC-Co coatings," Ceramics International, vol. 45, no. 11, pp. 13934-13941, 2019. 